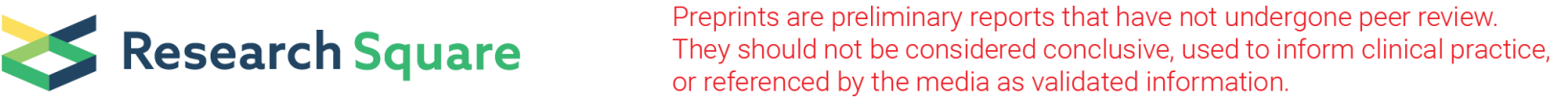

\section{How Important Is Income in Explaining Avoidance of Care Due to Cost-Sharing Payments? Results From a Mixed Methods Sequential Explanatory Study.}

Benjamin H. Salampessy ( $\sim$ b.h.salampessij@vu.nl )

VU Amsterdam

France R.M. Portrait

VU Amsterdam

Marianne Donker

VU Amsterdam

Ismail Ismail

VU Amsterdam

Eric J.E. Hijden

VU Amsterdam

\section{Research Article}

Keywords: Cost-sharing, Cost-related avoidance of healthcare, Mixed methods, Dominance analysis, Thematic analysis, Necessary care, Complexity of cost-sharing programs, Income, Financial leeway

Posted Date: March 11th, 2021

DOI: https://doi.org/10.21203/rs.3.rs-258936/v1

License: (c) (i) This work is licensed under a Creative Commons Attribution 4.0 International License.

Read Full License 


\section{Abstract \\ Background}

The avoidance of healthcare by patients because of the costs involved has become more prevalent in recent years. Certain patient characteristics, such as income, are known to be associated with a stronger demand-response to cost-sharing. In this study, we first assess the relative importance of patient characteristics with regard to the avoidance of healthcare due to cost-sharing payments, and then employ qualitative methods in order to understand these findings better.

\section{Methods}

Survey data was collected from a Dutch panel of frequent users of healthcare. Logistic regression models and dominance analyses were performed to assess the relative importance of patient characteristics with regard to the avoidance, i.e., personal characteristics, health, skills and financial situation. Semistructured interviews $(n=5)$ were conducted with those who had avoided healthcare. The verbatim transcribed interviews were thematically analyzed.

\section{Results}

Of the 7,339 respondents who completed the questionnaire, 1,048 respondents (14.3\%) had avoided healthcare because of the deductible requirement. Dominance analyses revealed that an individual's financial leeway contributed the most (34.8\%) to the model's overall McFadden's pseudo-R2 (i.e., 0.12), followed by income (25.6\%), age (19.6\%) and sense of mastery (8.9\%). Similar results were observed in stratified models and in population weighted models. Qualitative analyses distinguished four main themes: (1) the financial reasons and (2) personal considerations that affected the decision whether to use healthcare, (3) the perceived uncertainty in payments due to the complex design of cost-sharing programs, and (4) whether the use of healthcare was perceived as compulsory. Furthermore, 'avoidance of healthcare' seemed to have a negative connotation.

\section{Conclusion}

Our findings show that avoidance of healthcare depends on various factors including income, and imply that focusing solely on lowering cost-sharing payments for certain individuals will only partly reduce this avoidance. Our study underlines the need for a broader perspective in the design of cost-sharing programs.

\section{Background}


Many countries have responded to the rising costs of healthcare by implementing some form of costsharing in which insured individuals pay part of the costs involved as an out-of-pocket (OOP) expense [1, 2]. Cost-sharing payments (also referred to as users' fees or patient contributions) aim to increase the awareness of healthcare costs among those insured, and may consist of copayments (i.e., a fixed amount or a percentage of the costs per unit healthcare), deductibles (i.e., a predetermined amount paid by the individual after which the insurer covers all other costs) or a combination of both [3]. Rice and colleagues have shown that OOP spending has risen in many countries in the two last decades. In their analysis of high-income countries from the years 2000 onwards, they have found lowest growth rates in OOP spending among countries with historically high levels (e.g., the United States (US) and Switzerland) and highest growth rates for those with historically low OOP spending (e.g., the Netherlands, France and the United Kingdom) [4]. These trends have shifted a larger share of the costs to the insured individuals which forces them to devote an increasing portion of their annual income to these expenses and thereby make them more aware of the costs involved $[5,6]$. In turn, this may contribute to slowing down the rise of healthcare expenditures.

The rationale for implementing cost-sharing programs is underpinned by a large body of literature of which the RAND Health Insurance Experiment (RAND-HIE) has generated the methodological strongest evidence [1, 2]. The RAND-HIE has shown that cost-sharing payments reduce the demand for healthcare with, on average, no adverse health effects except for those with the lowest income and in poor initial health. The RAND-HIE has also revealed that this reduction occurs both in services with relatively little or no medical benefit for a patient's health as judged by physicians (hereafter referred to as nonrecommended healthcare), and in those with significant medical benefits (hereafter referred to as recommended healthcare) [7]. Cost-sharing has often been described in literature as an effective yet blunt policy instrument: such payments create effective incentives that influence the demand for healthcare, but do so in indiscriminate manner with respect to recommended and non-recommended healthcare.

More importantly, as certain individuals (e.g., low-income groups) are more likely to struggle to afford rising cost-sharing payments, these individuals are more prone to delay or completely forgo healthcare (hereafter referred to as avoidance of healthcare) because of these expenses $[4,5,8]$. Avoidance of healthcare judged as recommended in particular may then require additional and more expensive healthcare in the long run which could potentially offset any costs which are initially saved due to costsharing [9].

Besides studying OOP spending, Rice and colleagues have also investigated perceived cost-related problems affecting access to healthcare using country-specific consumer survey data of Commonwealth Fund. In these surveys, respondents have been asked if they have avoided healthcare such as hospital visits and medication due to costs. The US and Switzerland (i.e., countries with high OOP spending) rank as the top two in terms of cost-related avoidance, while France ranks third despite its relatively low OOP spending: In $2016,33 \%, 22 \%$ and $17 \%$ of the respondents respectively, had avoided healthcare due to costs $[4,10]$. 
Previous studies have linked (cost-related) avoidance of healthcare to certain patient characteristics such as income and age $[5,8,11]$. More importantly, various characteristics may interplay, i.e., reinforcing or neutralizing each other's effects. For example, on average, low-income groups may be more likely to avoid healthcare due to costs than high-income groups [3], but among those with a low income, some individuals may spend more money on non-essential or luxury items than others, i.e., their living standards may differ [12]. Consequently, they may have a smaller amount of money available for discretionary spending which makes them more likely to avoid healthcare due to costs compared to those with a low income and stricter spending habits. Hence, having more financial leeway may compensate for the effect of having a low income on the avoidance of healthcare.

This study aims at gaining insights into the extent to which an individual's income explains the avoidance of healthcare due to cost-sharing payments. Following a mixed methods sequential explanatory study design [13], we first use quantitative data to assess the relative importance of patient characteristics with respect to avoidance of healthcare; and then we employ qualitative methods while applying an interpretative approach to understand better and enrich the quantitative findings. Policy makers may therefore use our insights to identify individuals prone to avoid healthcare due to costsharing payments based on patient characteristics, and to determine whether current cost-sharing programs adequately minimize the avoidance of healthcare due to these payments among those insured.

\section{Dutch context}

In this study, we focused on the Dutch health system in which similarly to, for example, that in the US, the Dutch government has implemented provider competition. The reform of 2006 aims to stimulate effective competition between providers on price and quality, and to encourage patient choice. Universal access allows patients to use healthcare covered by the compulsory basic health insurance package across all hospitals. The content of this package is determined by the Ministry of Health. According to its guidelines, only services that are deemed necessary, effective, efficient and otherwise unaffordable for most citizens are covered. For most such services, the General Practitioner (GP) serves as gatekeeper, while a mandatory front-end deductible is applicable to all covered services with the exception of a specific few such as GP care [14-16].

In this study, we focused on healthcare services that were (1) ordered or prescribed by the treating physician (i.e., recommended healthcare), (2) covered by the insurance package and (3) subject to the deductible. Although Rice and colleagues have classified the cost-sharing level in the Netherlands as relatively low compared to other countries such as the US and Norway, they have observed a 'dramatic fluctuation' in the reported cost-related avoidance of healthcare [4]. In 2010, 6\% of the Dutch respondents indicated they had avoided healthcare due to cost-sharing payments. In 2013, this number peaked at $22 \%$, but then declined to $8 \%$ by 2016 . Rice and coauthors ascribe this pattern to the introduction of the deductible in 2008 and its relatively fast year-to-year increases thereafter. While initially capped at 155 euros when implemented, the deductible amount gradually increased to 170 euros in $2011(+9.7 \%$ in three years), then rapidly expanded to 220 euros in 2012 (+ 29.4\%) and 350 euros in $2013(+59.1 \%)$. In 
part due to political pressure, the deductible's threshold increased with relatively small increments to 385 euros $(+2.6 \%$ to $+4.2 \%$ per year) between 2014 to 2016 and has remained fixed since then $[4,14,17-19]$.

\section{Methods}

\section{Phase 1: Quantitative survey}

\section{Data collection}

We used data collected by Salampessy and colleagues and described in detail elsewhere [20]. In short, an online questionnaire was distributed by email among panel members of the Dutch Patient Federation in March and April 2016. This panel consisted of frequent users of healthcare who thus had been faced with cost-sharing requirements on a regular basis. Participation in the study was voluntary and any contributions were anonymized. Based on these conditions, approval by the 'Dutch Medical Research Involving Human Subjects Act' was not necessary. The questionnaire included, among others, questions regarding the characteristics of respondents and any cost-related avoidance of healthcare. It focused on three main types of healthcare services that were ordered or prescribed by the treating physician, covered by the basic health insurance package and subject to the front-end mandatory deductible: (1) medications, (2) diagnostic tests and (3) referrals to medical specialists for consultation or treatment (hereafter referred to as specialist care).

\section{Variables}

As our main outcome, we used the avoidance of recommended healthcare due to the deductible (hereafter referred to as deductible-related avoidance of healthcare). Respondents were classified as avoiders (coded as 1 ) if they had avoided one of the aforementioned types of services, and as users (coded as 0 ) if otherwise. To ensure that any reported avoidance was linked to the payment of the deductible, we used the following question in the questionnaire: "Have you forgone any healthcare recommended by a physician in the past two years due to mandatory deductible payments?". Similarly, for those labelled as users, we ensured that their use was linked to an actual payment of the deductible. To do so, we included only users that had to pay - either in full or in part - their deductible for the use of the given healthcare service as some respondents may already have paid their maximum deductible thus making any subsequent use 'free' of charge.

We used the various patient characteristics as determinants and divided them into four sets: (1) personal characteristics, (2) health, (3) skills and (4) financial situation. The first set included the variables gender, age (mean-centered, i.e., centered at the sample's mean age) and household situation (binary: "living alone" (reference) and "married or living together"). The second set (health) consisted of the two variables: presence of any chronic conditions (binary: "zero chronic conditions" (reference) and "one or more conditions") and subjective health (three categories that ranged from "(very) poor" to "(very) good"). The third set captured an individual's skills level measured by two variables: the highest attained educational level (three categories that ranged from "low" to "high") and sense of mastery level. The latter 
has been defined by Pearlin and Schooler as "the extent to which one regards one's life-chances as being under one's own control in contrast to being fatalistically ruled" (p5) [21], and was included as a proxy for an individual's ability to exercise control over his or her health state. To measure sense of mastery, the 7statements Pearlin Mastery Scale Test was used. In this test, each statement (e.g., "I have little control of events that happen to me") was scored on a five-point Likert scale. Subsequently, a total score was computed that ranged from 7 (low sense of mastery) to 35 (complete sense of mastery) [22]. Similar to age, sense of mastery was centered at the sample's mean value. The fourth set (financial situation) consisted of two variables: monthly net household income and financial leeway. Income was measured using five categories in total: four categories that ranged from "less than $€ 2000$ per month" to "more than $€ 4000$ per month", while a fifth category (labelled as "not-disclosed") could be used if respondents did not know or did not want to state their income. Financial leeway reflected an individual's financial status in terms of incurring debts or saving money. This variable was measured by four categories: three of them ranged from "incurring debts or using savings" to "saving money" and a fourth category "not-disclosed".

\section{Econometric analysis}

Of the 7,921 respondents described by Salampessy and colleagues [20], we included 7,339 respondents (i.e., avoiders and users) in our analyses. We performed a logistic regression model in which we used deductible-related avoidance of recommended healthcare as dependent variable and included all determinants as independent variables.

To determine the relative importance of each determinant, we conducted dominance analyses [23]; we expected several determinants to be correlated, e.g., income was expected to be positively correlated with health. Previous research has shown that standardized regression coefficients in a multiple linear regression analysis are frequently used in the literature to determine relative importance; a method that is appropriate on the condition that the predictors are not correlated [23, 24]. Alternatively, this method may lead to erroneous conclusions; it only captures the amount of the 'unique' (i.e., non-correlated) part of the explained variance by the given predictor, while the squares of the computed indices do not aggregate to the overall model fit statistic (i.e., coefficient of determination that is often referred to as the explained variance or R-squared (R2)). Dominance analyses take the correlations between predictors into account. This technique computes the predictor's contribution to the overall R2 and compares these contributions across all possible subset models (i.e., different combinations) for the given set of predictors. For dominance analyses based on logistic regressions models, McFadden's pseudo R2 ( $R 2 \mathrm{mf}$ ) is frequently used as a model fit statistic $[23,24]$.

In additional analyses, we repeated our models stratified by type of healthcare service. We also performed inverse probability weighted (IPW) models to make our findings more representative of the total Dutch population [25]. To compute the weights, we used iterative proportional fitting and ensured that the weighted marginal totals of our sample's age, gender and educational level closely resembled those of the total population [26]. 
All models were estimated in R [27]. Dominance analyses were performed using the "dominanceanalysis" package and $\mathrm{R} 2 \mathrm{mf}_{\mathrm{m}}$ as model fit statistic. To increase the internal validity of our findings, all models and dominance analyses were bootstrapped using 1000 bootstraps with replacement [28]. Iterative proportional fitting was performed using the "anesrake" package. Results were considered statistically significant if $p$-value $<0.05$.

\section{Phase 2: Qualitative follow-up}

\section{Sample}

Given that the answers to the questionnaire were anonymous, we included an additional question: respondents could enter their contact information if they wanted to participate, on voluntary basis, in a follow-up interview. The Dutch Patient Federation withheld any contact information (i.e., this was not disclosed to members of research team) and contacted eligible individuals.

We started with a stratified purposive sampling strategy [29]: which initially aimed to recruit a sample of individuals who had avoided healthcare and whose social economic status levels and financial situations ranged widely. Based on the preliminary findings, we narrowed our sampling strategy by focusing only on those who had either (1) a low social economic status or (2) just enough money to live on, or were incurring debts or using savings. In March 2017, ninety individuals were contacted by telephone for interviews regarding their avoidance of healthcare.

After the first round of phone calls $(n=30)$, we noticed that all the individuals were hesitant and refused to participate on hearing the topic of the interview.

In the following rounds, we therefore introduced the topic in more neutral terms: we asked whether individuals had ever not followed up on healthcare that had been prescribed, ordered or referred by a physician. By doing so, we tried to avoid any potential negative connotations that 'avoidance of healthcare'may have had. Given our quantitative-dominant study design, we followed a multiple case study approach: we interviewed only a small number of participants and did not set out to achieve data saturation.

\section{Data collection}

We first developed an interview guide (see Additional file 1) based on the relevant literature and the findings of our quantitative phase. To enrich the quantitative findings, we broadened the scope of our study: we asked about the occasions in which interviewees had not used healthcare in general (i.e., GP care, medication, diagnostic tests, specialist care, long-term care and home care) regardless of whether it had been prescribed or ordered by a physician, and whether its costs had played a role in their decision.

Two interviewers conducted the semi-structured guided interviews: MD was well-acquainted with qualitative methods, while a research intern was closely supervised by BS, MD and EH. Interviews were conducted face-to-face at the interviewee's home, audiotaped and transcribed verbatim. At the start of each interview, we informed interviewees that participation was voluntary and that their 
answers would be anonymized before being used for academic publication. Based on Dutch ethical principles of research, approval by the 'Dutch Medical Research Involving Human Subjects was not required. All interviewees signed a written informed consent. Afterwards, a written summary was sent to each interviewee who, if necessary, could correct and elaborate the summary (member check).

\section{Qualitative data analysis}

As we used an interpretative approach, we performed a thematic analysis to order data and organize coded data into themes with respect to the research question. We analyzed inductively (i.e., data-driven), but we purposely did not set out to aim of generating theory from our findings. For a better understanding of the data, data collection and analysis were performed iteratively, and the topic list was refined accordingly. To improve the dependability and confirmability of our findings [30], multiple members of the research team independently coded the data, while the coding was afterwards discussed to achieve consensus. In addition, we ensured that all distinguished themes were directly supported by verbatim data from the interviews. Analyses were performed in MAXQDA [31].

\section{Results}

\section{Phase 1: Quantitative results}

\section{Sample}

Of the 7,339 respondents included in the main analysis (Table 1), 1048 respondents (14.3\%) had avoided recommended healthcare due to the deductible (i.e., avoiders) and differed from those who did not (i.e., users). On average and relative to users, a larger share of avoiders was younger, female and living alone, had lower health levels and a lower prevalence of chronic conditions, had attained a lower educational level and scored lower on the mastery scale, had a lower income and were incurring debts or using savings. Most users had used prescribed medication, while most avoiders had avoided ordered diagnostic tests. Additional tables regarding respondents' characteristics are included in Additional file 2. Distributions of characteristics between users and avoiders remained similar in samples stratified by type of heath service relative to total sample. On average and relative to the total Dutch population, the study sample was older, consisted of more females and had attained a higher educational level. 
Table 1

Study population (quantitative phase)

\section{Group:}

Set 1: Personal characteristics

Age (in years) ***

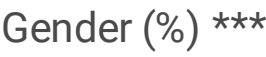

Male

Female

Living alone

Married or living together

Missing

Set 2: Health

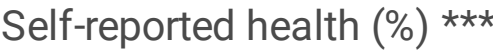

(Very) poor

Moderate

(Very) good

None

One or more

Chronic conditions (\%) ***

Low

Moderate

High

Missing

Mean (sd)

Sense of mastery (Pearlin's scale) ${ }^{A}$

***

Set 4: Financial situation

Monthly net household income (\%) *** <€2000

$€ 2001-€ 3000$

Set 3: Skills

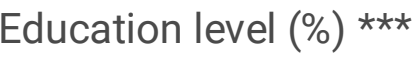

Users $(n=$ 6291)
Avoiders $(\mathrm{n}=$ 1048)

22.8

26.4

30.2

34.0

42.8

35.2

4.2

4.4

$22.6(5.7)$

$20.5(5.9)$

32.1

18.4

81.6
35.8

2.5 


\begin{tabular}{|c|c|c|c|}
\hline \multicolumn{2}{|l|}{ Group: } & $\begin{array}{l}\text { Users }(n= \\
6291)\end{array}$ & $\begin{array}{l}\text { Avoiders }(n= \\
\text { 1048) }\end{array}$ \\
\hline & $€ 3001-€ 4000$ & 13.6 & 5.0 \\
\hline & $>€ 4000 €$ & 7.6 & 2.1 \\
\hline & Not-disclosed & 18.0 & 14.3 \\
\hline \multirow[t]{4}{*}{ Financial leeway $(\%) \star \star \star ~$} & $\begin{array}{l}\text { Incurring debts or using } \\
\text { savings }\end{array}$ & 19.7 & 44.0 \\
\hline & Just enough to live on & 32.2 & 36.0 \\
\hline & Saving money & 46.3 & 18.5 \\
\hline & Not-disclosed & 1.8 & 1.5 \\
\hline \multicolumn{4}{|l|}{$\begin{array}{l}\text { Use and avoidance per type of } \\
\text { healthcare service }\end{array}$} \\
\hline \multirow[t]{3}{*}{$\mathrm{N}$ of individuals (\% of group) } & Prescribed medications & $5537(88.0)$ & $475(45.3)$ \\
\hline & Ordered diagnostic tests & $4189(66.6)$ & $738(70.4)$ \\
\hline & Specialist care & $3603(57.3)$ & $662(63.2)$ \\
\hline \multicolumn{4}{|c|}{$\begin{array}{l}\text { Chi square tests and independent } t \text {-tests were used to identify systematic differences between users } \\
\text { and avoiders. A = measured by the Pearlin Mastery Scale Test in which the lowest possible summed } \\
\text { score of } 7 \text { reflected a lacking sense of mastery, while the highest possible score of } 35 \text { reflected a } \\
\text { complete sense of mastery [22]. }\end{array}$} \\
\hline \multicolumn{4}{|c|}{$s d=$ standard deviation. ${ }^{* * *} p$-value $<0.05 .{ }^{* * *} p$-value $<0.01$} \\
\hline
\end{tabular}

\section{Relative importance}

As shown in Table 2, the main model revealed several significant associations. Regarding the first set of determinants (personal characteristics), age was negatively associated, i.e., a protective factor. Those older than the average aged respondent had lower odds of deductible-related avoidance of recommended healthcare (odds ratio, OR (95\% confidence intervals, $95 \% \mathrm{Cl}): 0.97(0.96-0.97))$. With respect to second set (health), relative to respondents in poor health, those in moderate health (OR $(95 \% \mathrm{Cl}): 1.57$ (1.30$1.91))$ and those in good health (OR $(95 \% \mathrm{Cl}): 1.49$ (1.19-1.88)) had higher odds of deductible-related avoidance of recommended healthcare, i.e., risk factor. In contrast, respondents with a chronic condition had lower odds (OR $(95 \% \mathrm{Cl})$ : $0.56(0.46-0.70))$ of demonstrating such decision behavior compared to those with no chronic condition. Regarding the third set (skills), sense of mastery (mean-centered) was a protective factor: OR $(95 \% \mathrm{Cl})$ : $0.96(0.94-0.97)$. With regard to the fourth set (financial situation), income and financial leeway were both protective factors: for example, respondents who were saving money had lower odds (OR $(95 \% \mathrm{Cl}): 0.28(0.23-0.35))$ of avoiding recommended healthcare due to the deductible compared to those either incurring debts or using their savings. 
Table 2

Results of logistic regression model and corresponding dominance analysis

\section{Analysis:}

Logistic regression

model

OR $(95 \% \mathrm{Cl})^{\mathrm{C}}$
Dominance analysis

Determinant's R2 ${ }_{\mathrm{mf}}$ (\% in overall) ${ }^{\mathrm{D}}$

Variables

Intercept

$0.45(0.33-$

$0.62)$

Set 1: Personal characteristics
Age (in years) ${ }^{A}$
Mean centered
$0.97(0.96-$
$0.02(19.6)$
Gender
Male (reference)
$0.00(1.6)$
Female
$1.03(0.90-$
1.19)

Household situation

Living alone (reference)

-

$0.00(1.9)$

$\begin{array}{ll}\text { Married or living together } & 0.89(0.76- \\ & 1.05) \\ \text { Missing } & 0.97(0.57- \\ & 1.54)\end{array}$

Set 2: Health

Self-reported health

(Very) poor (reference)

$0.00(2.8)$

Moderate

$1.57(1.30-$

1.91)

(Very) good

$1.49(1.19-$

1.88)

Chronic conditions

None (reference)

$0.00(3.4)$

One or more

$0.56(0.46-$

0.70 )

Dependent variable: 'deductible-related avoidance of recommended healthcare', i.e., avoidance of either prescribed medication, ordered diagnostic tests or specialist care due to the deductible. $A=$ centered at the total sample's mean age: 62.2 years (standard deviation: 11.1). $B=$ centered at the total sample's mean score: 22.3 (standard deviation: 5.8 ). $C=$ reflects bootstrapped confidence intervals. $D=$ reflects the bootstrapped values.

$O R=$ Odds ratio. $R 2_{m f}=M c F a d d e n ' s$ pseudo $R 2.95 \% \mathrm{Cl}=95 \%$ Confidence Intervals (lower bound upper bound). 


\section{Analysis:}

Logistic regression

model

Set 3: Skills

Education level

Low (reference)

$0.00(1.4)$

Moderate

$1.03(0.86-$

1.24)

High

$1.20(0.99-$

1.44)

Missing

$1.14(0.74-$

1.64)

Sense of mastery

(Pearlin's scale) $^{\mathrm{B}}$

Mean centered

$0.96(0.94-$

$0.97)$

Dominance analysis

Set 4: Financial

situation

Monthly net household $<€ 2000$ (reference)

$0.03(25.6)$

income

$\begin{array}{ll}€ 2001-€ 3000 & 0.49(0.40- \\ & 0.59) \\ € 3001-€ 4000 & 0.34(0.24- \\ & 0.46) \\ >€ 4000 & 0.29(0.18- \\ & 0.44) \\ \text { Not-disclosed } & 0.54(0.43- \\ & 0.65)\end{array}$

Financial leeway

$\begin{array}{ll}\begin{array}{l}\text { Incurring debts or using } \\ \text { savings (reference) }\end{array} & \cdot \\ \text { Just enough to live on } & 0.56(0.47- \\ & 0.65) \\ \text { Saving money } & 0.28(0.23- \\ & 0.35)\end{array}$

Dependent variable: 'deductible-related avoidance of recommended healthcare', i.e., avoidance of either prescribed medication, ordered diagnostic tests or specialist care due to the deductible. $A=$ centered at the total sample's mean age: 62.2 years (standard deviation: 11.1). $B=$ centered at the total sample's mean score: 22.3 (standard deviation: 5.8 ). $C=$ reflects bootstrapped confidence intervals. $D=$ reflects the bootstrapped values.

OR $=$ Odds ratio. $R 2_{m f}=$ McFadden's pseudo $R 2.95 \% \mathrm{Cl}=95 \%$ Confidence Intervals (lower bound upper bound). 


\begin{tabular}{|ll|}
\hline Analysis: & \multicolumn{1}{c|}{$\begin{array}{l}\text { Logistic } \\
\text { regression } \\
\text { model }\end{array}$} \\
\hline \multicolumn{1}{|c|}{ Not-disclosed } & $0.50(0.25-$ \\
\hline N of observations & $0.82)$
\end{tabular}

The corresponding dominance analysis (Table 2, column 4) revealed that financial leeway and income were the most important determinants as they contributed respectively $34.8 \%$ and $25.6 \%$ to the model's overall $\mathrm{R} 2_{\mathrm{mf}}$ (i.e., 0.12 ). Together with age and sense of mastery, the four most important determinants contributed $88.9 \%$ to the aforementioned statistic.

Results of additional analyses are included in Additional file 3 . With regard to stratified models, results were similar to those of the main model: (1) significant associations remained significant except for selfreported health for prescribed medication. Among the significant associations, (2) the same sign was observed and (3) the ORs closely resembled those of the main model. (4) A similar contribution in the model's overall R $2_{\mathrm{mf}}$ was observed for each the four most important determinants, i.e., financial leeway, income, age and sense of mastery. With respect to IPW analyses, the model revealed similar results relative those of the main model in terms of significant associations and corresponding direction, ORs and contribution in the model's overall $\mathrm{R} 2{ }_{\mathrm{mf}}$ with the one exception: self-reported health was not significant.

\section{Phase 2: Qualitative results}

\section{Sample}

While contacting eligible individuals, it was noted that many of them declined the offer to participate as they did not consider themselves to be avoiders of healthcare; the term 'avoidance of healthcare' was therefore perceived to have some negative connotation. Hence, the topic of the interview was reframed into more neutral terms. Afterwards, individuals $(n=12)$, agreed to be interviewed of whom seven later reconsidered and either declined or were unable to participate due to a hospital admission.

Five individuals were interviewed (Table 3): three women and two men were aged between 47 and 73 years, most of whom perceived their health as good to very good, had attained a low educational level, scored below-average on the sense of mastery scale relative to the average avoider in the quantitative 
phase, had a monthly net household income of less than 2000 euros, and had either just enough to live on or were incurring debts or using savings. Furthermore, R1 was considered to be a deviant case: relative to the average avoider and the other interviewees, R1 was older, scored higher on the sense of mastery scale and had a higher income and was able to save money.

Table 3

Study population (qualitative phase)

\begin{tabular}{|c|c|c|c|c|c|c|c|}
\hline Interviewee & $\begin{array}{l}\text { Age } \\
\text { (years) }\end{array}$ & Gender & $\begin{array}{l}\text { Self- } \\
\text { reported } \\
\text { health }\end{array}$ & $\begin{array}{l}\text { Education } \\
\text { level }\end{array}$ & $\begin{array}{l}\text { Sense of } \\
\text { mastery } \\
\text { (Pearlin's } \\
\text { scale) A }\end{array}$ & $\begin{array}{l}\text { Monthly } \\
\text { net } \\
\text { household } \\
\text { income }\end{array}$ & $\begin{array}{l}\text { Financial } \\
\text { leeway }\end{array}$ \\
\hline $\mathrm{R} 1$ & 73 & Male & $\begin{array}{l}\text { (Very) } \\
\text { good }\end{array}$ & High & 24 & $\begin{array}{l}€ 3001- \\
€ 4000\end{array}$ & $\begin{array}{l}\text { Saving } \\
\text { money }\end{array}$ \\
\hline R2 & 67 & Female & Moderate & Low & 13 & $<€ 2000$ & $\begin{array}{l}\text { Just } \\
\text { enough to } \\
\text { live on }\end{array}$ \\
\hline R3 & 47 & Male & $\begin{array}{l}\text { (Very) } \\
\text { good }\end{array}$ & Low & 14 & $<€ 2000$ & $\begin{array}{l}\text { Incurring } \\
\text { debts or } \\
\text { using } \\
\text { savings }\end{array}$ \\
\hline R4 & 59 & Female & $\begin{array}{l}\text { (Very) } \\
\text { poor }\end{array}$ & Moderate & 17 & $<€ 2000$ & $\begin{array}{l}\text { Incurring } \\
\text { debts or } \\
\text { using } \\
\text { savings }\end{array}$ \\
\hline R5 & 52 & Female & $\begin{array}{l}\text { (Very) } \\
\text { good }\end{array}$ & Low & 20 & $<€ 2000$ & $\begin{array}{l}\text { Just } \\
\text { enough to } \\
\text { live on }\end{array}$ \\
\hline
\end{tabular}

All individuals had one or more chronic conditions. $A=$ measured by the Pearlin Mastery Scale Test in which the lowest possible summed score of 7 reflected a lacking sense of mastery, while the highest possible score of 35 reflected a complete sense of mastery [22].

\section{Themes}

As shown in Table 4, four main themes were distinguished: (1) the financial reasons that affected the decision whether to use healthcare, (2) the perceived uncertainty in payments due to the complex design of cost-sharing programs, (3) the personal considerations that affected the decision whether to use healthcare and (4) whether the use of healthcare was perceived as compulsory. 
Table 4

Themes and subthemes

\section{Themes}

1. The financial reasons that affected the decision whether to use healthcare.

\section{Subthemes}

Coverage of the (additional) health insurance plan.

Amount of the cost-sharing or direct payment (in the case of a non-covered healthcare service).
2. The perceived uncertainty in payments due to the complex design of cost-sharing programs.

Uncertainty regarding the coverage of the basic health insurance package due to its complex design.

Uncertainty regarding the amount of the payments due to the complexity of the billing process.

3. The personal considerations that affected the decision whether to use healthcare.

Perceived medical necessity of healthcare.
Coping with their changed level of self-reliance due to a (chronic) condition.

Previous experiences with the physician, the healthcare service and the health insurer.

Fear of the consequences of the use of healthcare.

Travel time and parking availabilities.

4. The use of healthcare was perceived as compulsory.
Ride in a roller coaster.

\section{Theme 1: The financial reasons that affected the decision whether to use healthcare.}

The content (i.e., coverage) of the basic health insurance package or an additional health insurance plan, and any cost-sharing requirements (i.e., the amount of the payment) determined the costs of healthcare that, in turn, played a role for all interviewees. If interviewees had to pay, they indicated they were more likely to avoid the given healthcare service. However, relative to interviewees with a lower income or limited financial leeway, the costs of healthcare played a smaller role (i.e., less likely to avoid healthcare) for the respondent with a higher income and more financial leeway (R1).

(R5) "Although the GP disagreed, I postponed last year's blood test until the next year as this test was quite expensive relative to the deductible."

(R1) "I take the costs into account. As long as I can afford it, I do not mind paying for healthcare."

Four interviewees used healthcare on a regular basis such that they had to have paid the deductible in full in the last years. As a consequence, having to pay the deductible in itself played a small role in avoidance of healthcare.

(R2) "I pay the mandatory deductible fully each year but arrange payment in monthly installments". 


\section{Theme 2: The perceived uncertainty in payments due to the complex design of cost-sharing programs.}

The design of the cost-sharing program itself played a role as it indirectly affected the costs of healthcare: for most interviewees, the complexity of the program often caused uncertainty whether a given healthcare service was subject to cost-sharing and covered by the basic health insurance package or not. Most interviewees often only discovered about the costs when they had received the bill. They indicated that, if they had known about these costs in advance, they sometimes would not have used the healthcare service. On other occasions, some interviewees had avoided the given service beforehand as they were unsure whether costs would be reimbursed by their insurer and could not afford it otherwise. The uncertainty related to the design of the cost-sharing program did however not affect the decision to use healthcare of R1. In line with his above-average mastery and higher educational level relative to the other interviewees, R1 read the policy conditions of his insurance plan, actively sought additional information if necessary, and optimized the coverage for his medical use by switching between insurance plans.

(R3) "I was not fully sure if the costs of a treatment in a specialized center would be covered as information from different sources contradicted each other. Therefore, I did not follow up on the referral as I would not be able to afford it."

(R1) "My previous health insurance plan did not cover dental implants. I switched to a more expensive health insurance plan with additional benefits before receiving my dental implants. By doing so, my dental implants were fully covered."

\section{Theme 3: The personal considerations that affected the decision whether to use healthcare.}

The perceived medical need for healthcare was an important factor as all interviewees were of the opinion that they should not use more healthcare than necessary. After the GP had made the referral for a particular healthcare service, most interviewees would then make their own judgement regarding its medical necessity. If they agreed, interviewees would then use the healthcare service. Alternatively, most interviewees would not use or decide to stop using the given service if the expected or perceived medical benefits were too small. Hence, the perceived medical necessity could act as either a protective factor or as a risk factor.

(R1) "GP referred me to a dietician for my elevated my blood sugar levels. I did not follow up on the referral as I believed I could improve my diet myself."

(R5) "If my back issues arise, I would first wait and see whether the pain passes. I would only visit the GP if I believe that it is truly necessary."

Moreover, most interviewees showed signs of having to learn to cope with being less self-reliant and that they had to learn how to accept their need for frequent use of healthcare in order to live with their chronic conditions. 
(R4) "I have a wheelchair and a guide dog. It is not because I like to have them, but because I need them to be able to go somewhere."

(R5) "Although I know from previous experiences that I need healthcare to manage my pain. As I feel that I am not ready to act, I do not seek healthcare."

Previous experiences with the physician, the healthcare service or the health insurer also played a role for all interviewees and could act both as a protective factor and as a risk factor. For example, having a good patient-physician relationship encouraged interviewees to adhere to the prescribed therapy, and vice versa.

(R3) "I was reluctant to visit my former GP as he had once failed to detect my infection. I am very pleased with my new GP: I can contact him for all problems."

Similar to previous experiences, fear played a role in different ways. Two interviewees feared that they might become resistant to certain antibiotics or addicted to pain relief medication. These fears led them to use a smaller amount or use such medication less frequently than prescribed by the physician. In contrast, the interviewees' fear of cancer or recurrence of a tumor was a powerful incentive to their medication as prescribed.

(R4) "I frequently use antibiotics. Last year, I was hospitalized due to antibiotics-resistant bacteria. Without telling my physician, I decided it would be better if I stopped taking the antibiotics because I still need them to be able to work in the future."

(R1) "Although my GP had concluded that spot on my skin was not anything to worry about, I visited the dermatologist. Friends of mine also had spots on their skins which turned out to be cancerous."

For some interviewees, travel time and parking availabilities had played a role in their decision to avoid healthcare.

(R4) "I did not always follow up on my rehabilitation appointments as it took me three hours including waiting time to get there by bus."

Theme 4: The use of healthcare was perceived as compulsory.

On some occasions, interviewees believed that choosing not to use healthcare was not an option. They described the experience as emotionally intense as they experienced a 'roller coast' of emotions: a ride that they felt they simply forced to sit out.

(R2) "For a long time, you sit in a roller coaster. During that time, you solely focus on survival and endure all the blood tests, diagnostics tests and radiation treatments. Only afterwards, do you start to relive the whole process and realize that you have survived while others have not." 


\section{Discussion}

\section{Principal findings}

In the quantitative phase, we assessed the relative importance of patient characteristics with regard to avoidance of recommended healthcare due to the deductible. The logistic regression model showed that several significant relationships across the four sets of determinants. Being older, the presence of one or more chronic conditions, having a higher level of mastery, having a higher income and more financial leeway were all shown to be protective factors (i.e., decreased the odds) with respect to deductible-related avoidance of recommended healthcare, while having moderate or good self-reported health has shown to be a risk factor (i.e., increased the odds). The dominance analysis demonstrated that financial leeway contributed the most (34.8\%) to the model's overall $R 2_{m f}$ (i.e., 0.12 ), followed by income $(25.6 \%)$, age $(19.6 \%)$ and sense of mastery (8.9\%). Relative to the main model, the results of additional models stratified by type of healthcare service and of the IPW models revealed no meaningful differences.

In the qualitative phase, we conducted interviews to understand and enrich the quantitative findings. Four main themes were distinguished: (1) the financial reasons that affected the decision whether to use healthcare, (2) the perceived uncertainty in payments due to the complex design of cost-sharing programs, (3) the personal considerations reasons that affected the decision whether to use healthcare and (4) whether the use of healthcare was perceived as compulsory. Furthermore, 'avoidance of healthcare' seemed to have some negative connotation as the topic of the interview had to be reframed using more neutral terms.

\section{Possible explanations and comparison with the literature}

Our quantitative findings indicating the importance of financial leeway and income, correspond with previous studies that have linked factors such as the price of a given healthcare service, available household resources and income to the avoidance of healthcare [3, 8, 32]. Our quantitative findings also correspond with our qualitative findings as analyses distinguished financial factors as a relevant theme. In addition and in line with the RAND-HIE, we found a stronger response to cost-sharing among lowincome interviewees relative to those with higher incomes [3].

Moreover, dominance analyses revealed that financial leeway was more important than income. On the one hand, this implies that an individual who is able to save some money for future health expenses despite having a low income, is less likely to avoid healthcare due to these expenses, and vice versa. On the other hand, this finding reflects the impact that unexpected expenses (e.g., due to multiple costsharing payments) or a sudden drop in income (e.g., being self-employed with no clients) may have on an individual's financial situation and, in turn, with avoidance of healthcare due to the costs involved. These findings correspond with our qualitative findings. As frequent users of healthcare, interviewees often had to pay the full deductible. To minimize the impact of paying such deductibles on their financial leeway, 
most interviewees had arranged to pay by monthly installments. Having to pay the deductible in itself therefore played a minor role.

In line with literature [32,33], our qualitative analyses distinguished the complexity of cost-sharing programs as a relevant theme, and also showed that its relevance differed across educational level. Interviewees with a low to moderate educational levels had more difficulty in determining in advance whether, and if so, how much they had to pay for a given healthcare service. Because of uncertainty as to whether they could afford these costs, interviewees decided not to use the given healthcare service or stopped any future use. In contrast, the interviewee with a higher educational level was able to navigate effectively within the insurance plan. Although captured by educational level, this difference may reflect an underlying difference in health literacy and numeracy. Hibbard and colleagues have defined health literacy as "the ability to process and understand basic information needed to make appropriate health decisions" (p380) and numeracy as "the ability to process basic probability and numerical concepts" (p380) [34]. These authors have also shown that both constructs are correlated to educational level.

Across the three remaining sets of determinants (i.e., personal characteristics, health and skills), being older, having one or more chronic conditions and having a higher level of mastery were protective factors regarding deductible-related avoidance of recommended healthcare, while a better self-reported health level was a risk factor. It is reasonable to assume that, given their age and previous experience with the use of healthcare, older individuals and those with chronic condition are more likely to be aware of the potential adverse effects that the avoidance of recommended healthcare may result in compared to those who are younger or who have no chronic condition. Hence, they may be keener on maintaining their current level of health and thus be more incentivized to use the healthcare as recommended.

Regarding sense of mastery, our findings are in line with the literature: previous research has linked higher levels of mastery to better health levels, and suggests that those with such high levels are more capable (1) of effectively managing their health-related problems and (2) of using coping strategies to deal with these problems [35]. This mechanism also supports our qualitative findings as some interviewees had avoided healthcare because they had difficulties accepting their chronic conditions and the resultant problems.

Regarding self-reported health, our qualitative findings may provide an explanation. If the perceived medical benefits were too small considering their health level, interviewees would not use the given healthcare service despite their physician's judgement. More specifically, having a better state of health may reduce the perceived medical benefits of the given healthcare service that, in turn, leads to the avoidance of healthcare. This post-referral consideration of individuals may also explain why many eligible individuals declined to participate in our interviews as they did not classify themselves as avoiders of healthcare. Previous research has indicated that the term 'avoidance of healthcare' is often perceived as stigmatizing as it suggests that the individual acted irresponsibly and thus should be blamed for not using healthcare [36]. Hence, the seemingly rational consideration that individuals give to 
the matter after being referred, contradicts the common opinion that those who avoid healthcare are irresponsible.

Furthermore, the use of healthcare was often perceived as compulsory: a ride in a roller coaster of emotions that one is forced to sit out. According to some interviewees, this intense experience caused psychological issues that made accepting their chronic condition more difficult. In literature, experiences with healthcare, more specifically parental experiences following a child's admission to a pediatric intensive care unit, have also been described as akin to a turbulent emotional ride in a roller coaster [37].

\section{Implications}

Our findings have several implications. First, the observed importance of financial leeway indicates that adapting cost-sharing programs to income levels to reduce cost-related avoidance of recommended healthcare (e.g., lower payments for low-income groups) will only get one so far. Individuals who are faced with multiple expenses due to frequent use of healthcare find that they are left with little financial leeway. To prevent such accumulation of expenses, policy makers need to adopt a broader perspective in which they consider all healthcare expenses that an individual may have at a given time and design their cost-sharing programs accordingly. Moreover, as cost-sharing payments reduce the demand for both recommended and non-recommended healthcare [7], policy makers should also follow the design principles of value-based health insurance that directly link these payments to the 'value' of the given healthcare service [38, 39]. More specifically, healthcare services that yield high value (i.e., substantial medical benefits for a patient's health relative to their costs) should be subject to lower or no cost-sharing payments, while those with little value should be levied with higher payments.

Second, the relevance of the complexity of cost-sharing programs warrants additional efforts aimed at improving the transparency of these programs. For example, flat-fee copayments paid at point of care offer individuals clear and immediate information on the required payments in advance. In a hypothetical decision context, Salampessy and colleagues have demonstrated that such payments stimulate adherence to recommended healthcare [20].

Third, policy makers and physicians should be aware that various personal considerations and the perceived compulsory use of healthcare play a role in healthcare avoidance. Policy measures that improve patient-centered care in clinical practice may help physicians to address these issues during consultations.

\section{Strengths and limitations}

A strength of our study is the use of an explanatory sequential study design. The mix of quantitative and qualitative methods enhances the quality of our inferences and leads to a deeper understanding of our findings [40]. In addition, we followed principles of good practice in qualitative research [30]. For example, 
we sought feedback on the summary of the interview (member check) to improve the credibility of our findings. Also, we collected and analyzed data iteratively, and discussed the findings with multiple researchers; all of which improved the dependability and confirmability of our findings.

Certain limitations to our study should however be noted. With regard to the quantitative phase, our sample was not representative of the whole Dutch population. Although IPW models based on weighted representative sample in terms of age, gender and educational level produced similar results, we did not have population data for other relevant characteristics such as health and sense of mastery. However, as our sample consisted of frequent users of healthcare who have faced cost-sharing payments, their observed responses may resemble their decision behavior in real-life settings more closely, which improves the internal validity of our findings.

With respect to the qualitative phase, we did not achieve data saturation due to the small number of interviews. Also, due to this small number we may have missed other relevant perspectives such as those of young people. Both aspects reduce the transferability and dependability of our findings [30]. While more interviews conducted among a wider sample is required to capture all relevant themes (i.e., a fullscale qualitative study) and achieve data saturation, we believe that our qualitative data is rich enough considering its explanatory purpose: most quantitative findings have been supported by one or more subthemes.

\section{Conclusions}

Our findings show that an individual's financial leeway is more important than his or her income with respect to the deductible-related avoidance of recommended care, and also that individuals consider various factors when deciding whether or not to use healthcare. These findings imply that cost-sharing programs will only partly succeed in their goal of reducing the avoidance of healthcare due to costsharing payments if they focus solely on lowering these payments for certain individuals. Our study furthermore underlines the need for a broader perspective in the design of cost-sharing programs.

\section{List Of Abbreviations}

\section{GP}

General Practitioner

IPW

inverse probability weighted

OOP

out-of-pocket

OR

odds ratio

RAND-HIE

RAND Health Insurance Experiment 
R2

R-squared

$\mathrm{R} \mathbf{2}_{\mathrm{mf}}$

McFadden's pseudo R2

SD

standard deviation

US

United States

$95 \% \mathrm{Cl}$

$95 \%$ confidence intervals,

\section{Declarations}

\section{Ethics approval and consent to participate}

Ethical approval by a research ethics committee was deemed unnecessary because this study was not covered by Dutch Medical Research Involving Human Subjects Act (Wet medisch-wetenschappelijk onderzoek met mensen (WMO) [Dutch]], in BWBR0009408, https://wetten.overheid.nl/BWBR0009408/2020-01-01, in effect since March 1998, The Hague: Ministry of Health, Welfare and Sports: 1998). Consequently, no formal ethics review was sought. Respondents gave their informed consent by completing the questionnaire, while all interviewees signed a written informed consent.

\section{Consent for publication}

Not applicable

\section{Availability of data and materials}

The datasets used and/or analyzed during the current study are available from the corresponding author on reasonable request.

\section{Competing interests}

The authors declare that they have no competing interests.

\section{Funding}

The current study was not funded. 


\section{Authors' contributions}

CRediT statements: Salampessy: Conceptualization, Data Curation, Formal analysis, Investigation, Software, Writing - Original Draft. Portrait: Conceptualization, Formal analysis, Writing - Review \& Editing. Donker. Conceptualization, Investigation, Formal analysis, Writing - Review \& Editing. Ismail: Writing Review \& Editing. Van der Hijden: Conceptualization, Formal analysis, Investigation, Writing - Review \& Editing, Supervision.

\section{Acknowledgements}

The authors thank all respondents who completed the questionnaire and those who participated in the interviews. The authors thank Hidde Hofstede for this help during the project.

\section{References}

1. McGuire TG: Chapter Five - Demand for Health Insurance1. In: Handbook of Health Economics. Volume Volume 2, edn. Edited by Mark V. Pauly TGM, Pedro PB: Elsevier; 2011: 317-396.

2. Cutler DM, Zeckhauser RJ: The anatomy of health insurance. In: Handbook of Health Economics. Volume 1, edn.; 2000: 563-643.

3. Manning WG, Newhouse JP, Duan N, Keeler EB, Leibowitz A: Health Insurance and the Demand for Medical Care: Evidence from a Randomized Experiment. Am Econ Rev 1987, 77(3):251-277.

4. Rice T, Quentin W, Anell A, Barnes AJ, Rosenau P, Unruh LY, van Ginneken E: Revisiting out-of-pocket requirements: trends in spending, financial access barriers, and policy in ten high-income countries. BMC Health Serv Res 2018, 18(1):371. doi:10.1186/s12913-018-3185-8

5. Palladino R, Lee JT, Hone T, Filippidis FT, Millett C: The Great Recession And Increased Cost Sharing In European Health Systems. Health Aff 2016, 35(7):1204-1213. doi:10.1377/hlthaff.2015.1170

6. Tambor M, Pavlova M, Woch P, Groot W: Diversity and dynamics of patient cost-sharing for physicians' and hospital services in the 27 European Union countries. Eur J Public Health 2010, 21(5):585-590. doi:10.1093/eurpub/ckq139

7. Newhouse JP, Group RCIE: Free for all?: lessons from the RAND health insurance experiment: Harvard University Press; 1993.

8. Baird K: High Out-of-Pocket Medical Spending among the Poor and Elderly in Nine Developed Countries. Health Serv Res 2016, 51(4):1467-1488. doi:10.1111/1475-6773.12444

9. Chandra A, Gruber J, McKnight R: Patient cost-sharing and hospitalization offsets in the elderly. Am Econ Rev 2010, 100(1):193-213. doi:10.1257/aer.100.1.193

10. The Commonwealth Fund: International Health Policy Survey of Adults 2016. In.; 2016.

11. Lehnert T, Heider D, Leicht H, Heinrich S, Corrieri S, Luppa M, Riedel-Heller S, König H-H: Review: Health Care Utilization and Costs of Elderly Persons With Multiple Chronic Conditions. Med Care Res 
Rev 2011, 68(4):387-420. doi:10.1177/1077558711399580

12. Carle AC, Bauman KJ, Short K: Assessing the Measurement and Structure of Material Hardship in the United States. Social Indicators Research 2009, 92(1):35-51.

13. Creswell JW: Research design : qualitative, quantitative, and mixed method approaches, 4th ed., international student edition. edn. Los Angeles: Sage; 2014.

14. Kroneman M, Boerma W, van den Berg M, Groenewegen P, de Jong J, van Ginneken E: Netherlands: health system review, vol. 18. Copenhagen: World Health Organization. Regional Office for Europe; 2016.

15. Enthoven AC, van de Ven WPMM: Going Dutch - Managed-Competition Health Insurance in the Netherlands. N Engl J Med 2007, 357(24):2421-2423. doi:10.1056/NEJMp078199

16. van de Ven WPMM, Beck K, Buchner F, Schokkaert E, Schut FT, Shmueli A, Wasem J: Preconditions for efficiency and affordability in competitive healthcare markets: Are they fulfilled in Belgium, Germany, Israel, the Netherlands and Switzerland? Health Policy 2013, 109(3):226-245. doi:10.1016/j.healthpol.2013.01.002

17. Van de Ven WPMM, Schut FT: Managed competition in the Netherlands: still work-in-progress. Health Econ 2009, 18(3):253-255. doi:10.1002/hec.1446

18. Ministry of Health: Translated: Amendments to the Health Insurance Act in order for the mandatory deductible to remained unchanged up to and including 2021. In.; 2018.

19. IQ Healthcare: International Health Policy Survey 2016 In. Nijmegen; 2016.

20. Salampessy BH, Alblas MM, Portrait FRM, Koolman X, van der Hijden EJE: The effect of cost-sharing design characteristics on use of health care recommended by the treating physician; a discrete choice experiment. BMC Health Serv Res 2018, 18(1):797. doi:10.1186/s12913-018-3598-4

21. Pearlin LI, Schooler C: The structure of coping. J Health Soc Behav 1978:2-21. doi:10.2307/2136319

22. Pearlin LI, Menaghan EG, Lieberman MA, Mullan JT: The stress process. J Health Soc Behav 1981:337-356. doi:10.2307/2136676

23. Budescu DV: Dominance analysis: A new approach to the problem of relative importance of predictors in multiple regression. Psychol Bull 1993, 114(3):542-551. doi:10.1037//00332909.114.3.542

24. Azen R, Traxel N: Using Dominance Analysis to Determine Predictor Importance in Logistic Regression. Journal of Educational and Behavioral Statistics 2009, 34(3):319-347. doi:10.3102/1076998609332754

25. Cole SR, Hernán MA: Constructing Inverse Probability Weights for Marginal Structural Models. Am J Epidemiol 2008, 168(6):656-664. doi:10.1093/aje/kwn164

26. Statistics Netherlands: StatLine. In.; 2021.

27. R Core Team: R: A language and environment for statistical computing. R Foundation for Statistical Computing. In. Vienna, Austria; 2020.

28. Efron B, Tibshirani RJ: An introduction to the bootstrap. Boca Raton, Florida: CRC press; 1994. 
29. Palinkas LA, Horwitz SM, Green CA, Wisdom JP, Duan N, Hoagwood K: Purposeful Sampling for Qualitative Data Collection and Analysis in Mixed Method Implementation Research. Adm Policy Ment Health 2015, 42(5):533-544. doi:10.1007/s10488-013-0528-y

30. Frambach JM, van der Vleuten CPM, Durning SJ: AM Last Page: Quality Criteria in Qualitative and Quantitative Research. Academic Medicine 2013, 88(4). doi:10.1097/ACM.0b013e31828abf7f

31. VERBI Software: MAXQDA 2020. In. Berlin, Germany; 2019.

32. Jacobs B, Bigdeli M, Annear PL, Van Damme W: Addressing access barriers to health services: an analytical framework for selecting appropriate interventions in low-income Asian countries. Health Policy Plan 2011, 27(4):288-300. doi:10.1093/heapol/czr038

33. Schoen C, Osborn R, Squires D, Doty MM, Pierson R, Applebaum S: How health insurance design affects access to care and costs, by income, in eleven countries. Health Aff 2010, 29(12):2323-2334. doi:10.1377/hlthaff.2010.0862

34. Hibbard JH, Peters E, Dixon A, Tusler M: Consumer competencies and the use of comparative quality information: it isn't just about literacy. Med Care Res Rev 2007, 64(4):379-394. doi:10.1177/1077558707301630

35. Backe IF, Patil GG, Nes RB, Clench-Aas J: The relationship between physical functional limitations, and psychological distress: Considering a possible mediating role of pain, social support and sense of mastery. SSM - Population Health 2018, 4:153-163. doi:10.1016/j.ssmph.2017.12.005

36. Klop HT, Evenblij K, Gootjes JRG, de Veer AJE, Onwuteaka-Philipsen BD: Care avoidance among homeless people and access to care: an interview study among spiritual caregivers, street pastors, homeless outreach workers and formerly homeless people. BMC Public Health 2018, 18(1):1095. doi:10.1186/s12889-018-5989-1

37. Alzawad Z, Lewis FM, Kantrowitz-Gordon I, Howells AJ: A Qualitative Study of Parents' Experiences in the Pediatric Intensive Care Unit: Riding a Roller Coaster. Journal of Pediatric Nursing 2020, 51:814. doi:10.1016/j.pedn.2019.11.015

38. Choudhry NK, Rosenthal MB, Milstein A: Assessing The Evidence For Value-Based Insurance Design. Health Aff 2010, 29(11):1988-1994. doi:10.1377/hlthaff.2009.0324

39. Lee JL, Maciejewski ML, Raju SS, Shrank WH, Choudhry NK: Value-Based Insurance Design: Quality Improvement But No Cost Savings. Health Aff 2013, 32(7):1251-1257. doi:10.1377/hlthaff.2012.0902

40. Teddlie C, Tashakkori A: SAGE Handbook of Mixed Methods in Social \& Behavioral Research. In. Edited by Teddlie C, Tashakkori A, 2 edn. Thousand Oaks, California; 2010.

\section{Supplementary Files}

This is a list of supplementary files associated with this preprint. Click to download.

- Additionalfile1.docx 
- Additionalfile2.docx

- Additionalfile3.docx 